\title{
A Simple Empirical Model of Data Fouling by High- Grading in Capture Fisheries
}

\section{Michael Wernerheim and Richard L. Haedrich}

This article appeared in the 83 (1) issue. An incorrect version of figure 1 appeared on page 78. This figure should have appeared instead.

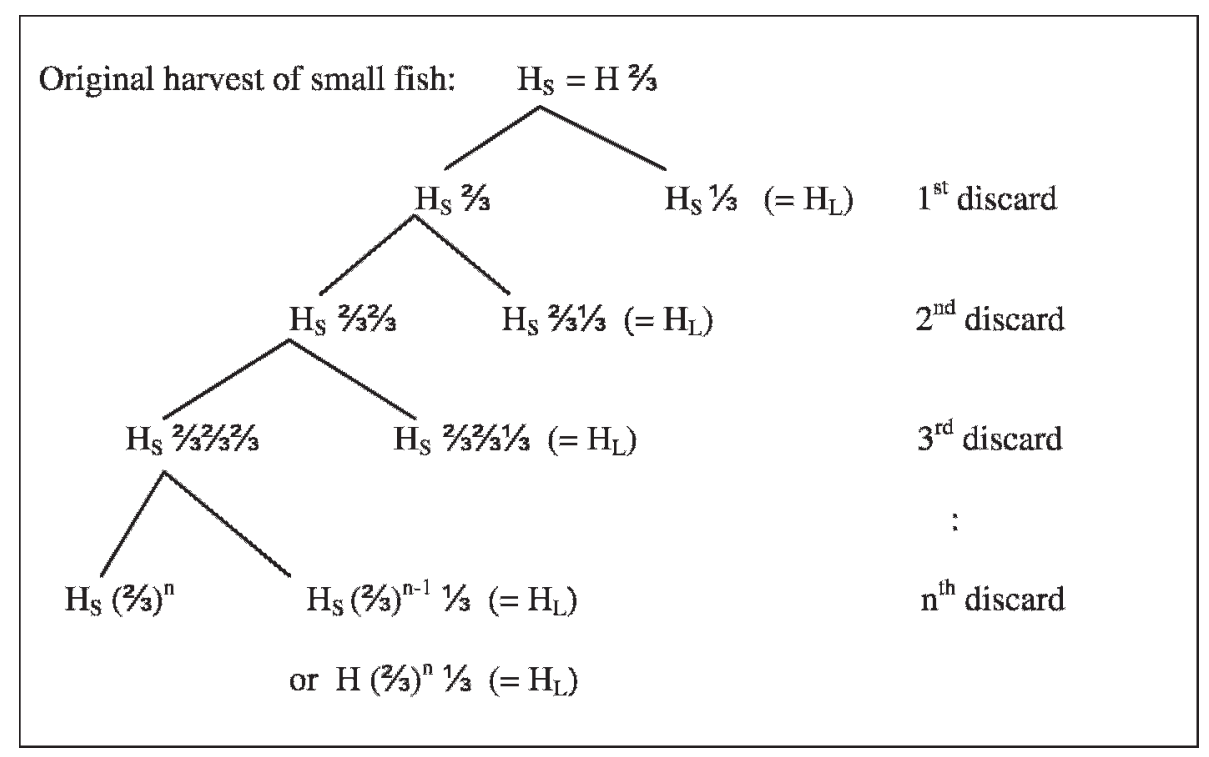

